УДК 371.487
https://doi.org/10.36906/FKS-2021/33

Евстигнеева О.Н.

Детский садик № 40 «Золотая рыбка»,

2. Нижневартовск, Россия

\title{
ОПТИМИЗАЦИЯ ТЕХНОЛОГИИ КРУГОВОЙ ТРЕНИРОВКИ ДЛЯ ВОСПИТАННИКОВ ДОШКОЛЬНОГО УЧРЕЖДЕНИЯ
}

Аннотация. В статье представлен опыт по применению оптимизированного метода круговой тренировки в работе с детьми дошкольного возраста. Данный подход позволяет повысить физическую нагрузку на организм ребенка, сформировать двигательный потенциал, развить физические качества и повысить оздоровительный эффект от занятий. Применение карт-схем расширяет интеллектуальные особенности ребенка в запоминании движений и их воспроизводства.

Ключевые слова: дошкольники, круговая тренировка, физическое воспитание.

Evstigneeva O.N. Kindergarten №40 “Goldfish”, Nizhnevartovsk, Russia

\section{OPTIMIZATION OF CIRCULAR TRAINING TECHNOLOGY FOR PRESCHOOL CHILDREN}

Annotation. The article presents the experience of using the optimized method of circular training in working with preschool children. This approach allows you to increase the physical load on the child's body, form motor potential, develop physical qualities and increase the health effect of classes. The use of circuit maps expands the intellectual features of the child in memorizing movements and their reproduction.

Keywords: preschoolers, circular training, physical education.

Системное использование научных достижений для социального и экономического развития общества, интеллектуального развития индивида, требует создания стимулов для распространения и приобретения знаний. Современная система образования, сегодня начинается в дошкольных образовательных учреждениях, a значит, предъявляются определенные требования для обеспечения качества подготовки воспитанника. Выбор эффективных направлений в физическом воспитании дошкольника будет способствовать успешному развитию ребенка.

Приоритетными в реализации образовательных задач в физическом воспитании дошкольников, становятся следующие положения:

- подбор эффективных форм, средств, методов и технология обучения и воспитания дошкольников;

- целенаправленное и гармоничное развития двигательных качеств детей;

- совершенствование и формирование новых двигательных умений и навыков;

- достижение наилучшего оздоровительного эффекта от занятий физической культурой. 
В результате многолетних наблюдений за организацией и качеством проведения занятий физической культурой с дошкольниками, определились ряд недостатков, которые сказываются на качестве процесса физического воспитания дошкольников: недостаточная моторная плотность занятий по физическому развитию; недостаточная индивидуализация педагогического воздействия; недостаточная одновременное и самостоятельное выполнение упражнений большим числом занимающихся, с использованием максимального количества оборудования и инвентаря.

Изучая мнения передовых ученых в данной области, следует отметить мнения В.К. Бальсевича, который в своих работах утверждает, что спортизация является одним из перспективных инновационных направлений совершенствования физического воспитания [1, с. 164]. Л.И. Лубышева отмечает, что в процессе адаптирования технологических достижений в области спорта, в интересах целенаправленного преобразования физического потенциала человека, принципиальное место должно занять признание приоритета тренировки как ведущего и самого эффективного способа такого преобразования [2, с. 10]. Необходимость использования оздоровительной тренировки с целью совершенствования физического воспитания детей дошкольного возраста, сегодня признается многими специалистами. Это связано прежде всего с тем, что методика проведения занятий по физическому воспитанию, сложившаяся в системе дошкольного образования, не способствует в достаточно полной мере реализации оздоровительных задач, поскольку направлена главным образом на освоение двигательных навыков и по своей физической нагрузке недостаточна для достижения тренированности организма детей.

На основании вышесказанного следует заключить, что в процессе физического воспитания дошкольников нужно эффективно применять игровые формы, а также игры с элементами видов спорта (баскетбол, бадминтон, футбол), адаптированные к дошкольникам с учетом их двигательных возможностей и с оптимальной физической нагрузкой. Применение адаптированной круговой тренировки в физическом воспитании дошкольников может быть эффективна, так как представляет собой организационно-методическую форму образовательной деятельности, направленной в основном на комплексное развитие двигательных качеств. Круговая тренировка - это не что иное, как постоянная смена одного вида физической нагрузки на другой. В результате использования нескольких видов физической нагрузки и повторения их в одном и том же порядке много раз круг замыкается, и получается круговой метод тренировки. Таким образом, круговая тренировка - это выполнение нескольких видов физических упражнений сериями, по кругу. Концепция тренировки - пока единственная научно обоснованная концепция управления развитием физического потенциала человека. Методической основой круговой тренировки является многократное выполнение определенных движений, в условиях точного дозирования нагрузки и точно установленного порядка ее изменения и чередования с отдыхом. Поэтому круговая тренировка представляет собой организационно-методическую форму образовательной деятельности, направленной в основном на комплексное развитие двигательных качеств. Стандартное содержание круговой тренировки:

- последовательное выполнение упражнений в процессе прохождения «станций», расположенных по кругу;

- использование хорошо освоенных упражнений;

- последовательное включение в работу различных мышечных групп;

- регламентация работы и отдыха на каждой «станции»;

- индивидуализация тренировочной нагрузки;

- систематическое и постепенное повышение тренировочных требований. 
Целью занятий по физическому воспитанию дошкольников с применяем адаптированного метода круговой тренировки явилось: повышение двигательной деятельности детей и уровня физической подготовленности в соответствии с образовательной областью «Физическая культура» через активные формы работы с воспитанниками 4-7лет.

Поставленная цель реализовывалась через решение следующих задач: сохранение и укрепление здоровья детей, улучшение их двигательного статуса с учётом индивидуальных возможностей и способностей; совершенствование физических качеств; закрепление двигательных умений и навыков.

Таблица

Содержание этапов оптимизации примения круговой тренировки

Этапы оптимизации круговой тренировки

I этап ПОДГОТОВИТЕЛЬНЫЙ (4-5 лет)

Ознакомление воспитанников с картами-схемами, обозначающими основные движения и базовым элементом круговой тренировки: групповым способом организачии детей.

Блок 1: ознакомление с

картами-схемами, на каждой из которых изображение

обозначающее основной вид движение; введение работы по группам.

Блок 2: включение известных
детям карт-схем в
непосредственно
образовательную деятельность;
отработка умения работать по
группам.

Блок 3: включение работы в группах по карте-схеме с изображением, обозначающим один основной вид движения.

\section{II этап БАЗОВЫЙ (5-6 лет)}

Введение карт-схем с группой изображений (от 1 до 3-х) обозначающих основные виды движения при групповом способе организации работы с воспитанниками.

Блок 1: закрепление навыка работы в группах по картесхеме с изображением, обозначающим один основной вид движения.

Блок 2: отработка навыка
работы в группах по карте-
схеме с изображением,
обозначающим один -два
основных вида движения.
Ознакомление с понятием
станция; правильным выбором
спортивного инвентаря для
предстоящей деятельности
согласно картам-схемам.

III этап ОСНОВНОЙ (6-7 лет) работы в группах по картесхеме с изображением, обозначающим два -три основных вида движения. Самостоятельный выбор спортивного инвентаря для предстоящей деятельности согласно картам-схемам.

\begin{tabular}{|c|c|c|}
\hline \multicolumn{3}{|c|}{ III этап ОСНОВНОЙ (6-7 лет) } \\
\hline $\begin{array}{l}\text { Блок 1: отработка навыка } \\
\text { работы в группах по карте- } \\
\text { схеме с изображением, } \\
\text { обозначающим два -три } \\
\text { основных вида движения. } \\
\text { Самостоятельный подбор } \\
\text { спортивного инвентаря для } \\
\text { предстоящей деятельности } \\
\text { согласно картам-схемам. }\end{array}$ & $\begin{array}{l}\text { Блок 2: отработка навыка } \\
\text { самостоятельной работы в } \\
\text { одной группе по карте-схеме с } \\
\text { изображением, обозначающим } \\
\text { три основных вида движения. } \\
\text { (Визуальный контроль) } \\
\text { Самостоятельный подбор и } \\
\text { размещение спортивного } \\
\text { инвентаря на «станциях» для } \\
\text { предстоящей деятельности } \\
\text { согласно картам-схемам. } \\
\text { (Визуальный контроль). }\end{array}$ & $\begin{array}{l}\text { Блок 3: отработка навыка } \\
\text { самостоятельной работы в } \\
\text { группах, по карте-схеме, с } \\
\text { изображением, обозначающим } \\
\text { три - четыре основных вида } \\
\text { движения. (Визуальный } \\
\text { контроль). Самостоятельный } \\
\text { подбор и размещение } \\
\text { спортивного инвентаря на } \\
\text { «станциях» для предстоящей } \\
\text { деятельности согласно картам- } \\
\text { схемам. } \\
\text { (Визуальный контроль). }\end{array}$ \\
\hline
\end{tabular}


Для достижения результата осуществляла с детьми игровую, познавательноисследовательскую деятельность. Эффективность круговой тренировки заключается в:высокой моторной плотности физического развития;индивидуализации педагогического воздействия; относительно точном дозировании физической нагрузки; согласовании содержания упражнений на «станциях» с программными задачами; одновременное и самостоятельное выполнение упражнений большим числом занимающихся, с использованием максимального количества оборудования и инвентаря [3, с. 35].

Также высока возможность дифференцировать нагрузку в процессе образовательного процесса путем: изменения темпа упражнений; изменения интервалов отдыха; введение дополнительных «станций» с облегченной или, наоборот, более высокой нагрузкой; варьирования способов и условий выполнения упражнений.

Идеей опыта использования оптимизированной круговой тренировки с дошкольниками является использование принципа интеграции: введение карт-схем в технологию круговой тренировки, посредством чего расширяется диапазон воспитанников, приобщаемых к данной технологии, представленные в таблице. Так, при оптимизации технологии на первом этапе подключаются воспитанники 4-5 лет путем ознакомления с элементами технологии: картами - схемами.

Реализация опыта будет способствовать формированию у дошкольников развития целевых ориентиров к окончанию образовательных отношений. Круговая тренировка с использованием карт-схем в работе с детьми со среднего дошкольного возраста, позволяет оптимально решать задачи дошкольного физического воспитания, включающие разностороннюю физическую подготовку детей и гармоничное развитие двигательных качеств. Способствует повышению интереса у детей к занятиям спортом.

Применение круговой тренировки в физическом воспитании детей старшего дошкольного возраста способствует повышению его эффективности, что выражено в положительной динамике показателей функционального состояния и физической подготовленности дошкольников и формировании интереса детей к занятиям физическими упражнениями.

\section{Литература}

1. Бальсевич В.К., Лубышева Л.И. От физического воспитания к созданию отечественной системы спортивного образования в школе // Евразийский форум. 2009. № 1. C. 153-168.

2. Лубышева Л.И., Загревская А.И., Передельский А.А., Манжелей И.В., Литвиненко С.Н., Черепов Е.А., Пешкова Н.В., Родионова М.А., Поливаев А.Г., Кондратьев А.Н., Базилевич М.В. Спортизация в системе физического воспитания: от научной идеи к инновационной практике. М.: Теория и практика физической культуры и спорта, 2017. С. 200.

3. Шарманова С.Б., Федоров А.И. Инновационные подходы в физическом воспитании детей дошкольного возраста // Физическая культура: воспитание, образование, тренировка. 2004. № 4. C. 33-41.

(C) Евстигнеева О.Н., 2021 